\title{
Abnormal Behaviours in Two Captive Brown Bear (Ursus arctos Linnaeus, 1758) Females: Individual Differences and Seasonal Variations
}

\section{Abnormales Verhalten in zwei gefangen Grizzlybär-Weibchen (Ursus arctos Linnaeus, 1758): einzelne Unterschiede und saisonale Variationen}

\author{
Ana I. Soriano ${ }^{\mathrm{a}, *}$, Dolors Vinyoles ${ }^{\mathrm{a}}$, Carmen Maté ${ }^{\mathrm{b}}$ \\ a Department of Animal Biology, University of Barcelona, Barcelona, Spain \\ b Barcelona Water Cycle, Anonymous Society, Barcelona, Spain
}

Received 6 September 2016

\begin{abstract}
Abnormal behaviours are common in captive environments that not supply the physical and psychological needs of animals. There are animals, like brown bears, more susceptible to develop abnormal behaviours due to their seasonal biology related to food, hibernation or reproduction. The two brown bear Ursus arctos females from Barcelona Zoo, Spain, showed two different patterns of abnormal behaviours. The old o displayed episodes of biting a tree trunk while the young o carried out headtossing events. The studied period was from March to December 2004 divided into seasonal periods: autumn, spring and summer. A total of 63 hours of observations were recorded using a multi-focal continuous method. The time invested on abnormal behaviour was higher in spring followed by summer and autumn in both females. The other variables related to the abnormal behaviour studied were duration, intensity, occurrence and space use which also showed statistically significant differences among seasonal periods. The old o space use during abnormal behaviour was in the same zone meanwhile the young o showed statistically significant differences among seasonal variations and zones of the enclosure. These results should be taken into account to improve the management of bears in zoological institutions.
\end{abstract}

Keywords: Episodes; Events; Stereotypies; Zoo management; Space use

\footnotetext{
* Corresponding author.

E-mail address: anaisabel_soriano@yahoo.es (A.I. Soriano).
} 


\section{Introduction}

In order to achieve good animal welfare in zoological institutions it is necessary to understand the physical and psychological needs of the animals and provide appropriate management. Studies carried out in the natural habitat of species provide good indicators for the species-specific requirements that should be supplied in zoological institutions. In many cases, the wild-captive comparison is a useful tool as an animal-welfare indicator (Broom, 1983; Veasey, Waran, \& Young, 1996).

Abnormal behaviours are not observed in the typical behaviour patterns of wild or freeroaming animals (Criswell \& Galbreath, 2005; Meyer-Holzapfel, 1968) and the occurrence of such behaviour is considered an indicator of poor animal welfare in zoological institutions. Broom (1983) suggested that it is unacceptable for any animal to spend more than $10 \%$ of the waking day displaying abnormal behaviours. There are different categories of the abnormal behaviours, including abnormal escape reactions, refusal of food, excessive aggression, stereotypic motor reactions (i.e. head-toss, pacing or straight-line, figure-ofeight, circular and oval circuits), self-mutilation, abnormal sexual behaviour (i.e. substitute sexual objects), apathy, aggression, oral stereotypes (i.e. biting, coprophagy, regurgitation and reingestion, or licking), abnormal mother-infant relationships and prolonged infantile behaviour (Fox, 1968). It is necessary to identify and classify abnormal behaviours correctly because, in many situations, some behavioural expressions can be the result of physical disease (e.g. dental problems, arthritis or hormonal dysfunctions). Physical afflictions can be detected through veterinary diagnoses and are different from the mental conditions associated with abnormal behaviour, which implicate a complex neurobiological basis (Mason \& Latham, 2004). One kind of abnormal behaviour is stereotypic behaviour, which is sometimes observed in zoological institutions and characterized by morphologically identical movements repeated regularly without any apparent function (Lawrence \& Rushen, 1993; Mason, 1991; Mason \& Rushen, 2006).

Members of the Ursidae family are more likely to exhibit abnormal behaviours, such as pacing or begging, in zoological institutions because their complex needs, particularly related to seasonal variations in activity (hibernation), feeding (omnivorous) or reproduction (polygamous), crepuscular habits and the extensive territories in nature (territorial behaviour), are difficult to provide artificially (Vickery \& Mason, 2003a; Ward \& Kynaston, 2003).

Individual variations in abnormal behaviours have also been observed in the Ursids literature. Sixty six brown bears Ursus arctos from 28 zoological parks showed individual patterns (Montaudouin \& Le Pape, 2005), and also seen in other species; for example, Giant pandas Ailuropoda melanoleuca (Lindburg, Swaisgood, Zhang, Narushima, \& Xiaoping, 2003), Malayan sun bears Helarctos malayanus (Cheng, 2003), Asiatic black bears $U$. thibetanus and Malayan sun bears (Vickery \& Mason, 2003b), and Polar bears U. maritimus (Wechsler, 1991). Moreover, individual patterns in abnormal behaviours can be caused mainly by seven factors: gender, hormonal levels, age, nervous-system malfunction, time spent in captivity, type of rearing or life experience (see Table 1).

There are few studies that have studied the effects of season variation on bear abnormal behaviours. So, there are two publications in Polar bears where abnormal behaviours were 
Table 1. Seven influential factors in the development of abnormal behaviours in captive Ursids.

\begin{tabular}{|c|c|c|}
\hline Factor & Definition & Reference \\
\hline Gender & $\begin{array}{l}\text { In zoological institutions, male Polar bears } \\
\text { showed more abnormal behaviours during the } \\
\text { spring mating season than females }\end{array}$ & Ames (1993) \\
\hline Hormone levels & $\begin{array}{l}\text { There is more testosterone in male bears during } \\
\text { the breeding period, which can cause a higher } \\
\text { prevalence of the abnormal behaviours }\end{array}$ & $\begin{array}{l}\text { Lawrence and } \\
\text { Rushen (1993) }\end{array}$ \\
\hline Age & $\begin{array}{l}\text { The effect of captivity seems to be more } \\
\text { profound for a young bear than for mature } \\
\text { animals, in terms of the expression and } \\
\text { persistence of abnormal behaviours }\end{array}$ & $\begin{array}{l}\text { Ridley and } \\
\text { Baker (1982) }\end{array}$ \\
\hline $\begin{array}{l}\text { Nervous-system } \\
\text { malfunction }\end{array}$ & $\begin{array}{l}\text { Usually provokes the appearance of an } \\
\text { abnormal behaviour }\end{array}$ & $\begin{array}{l}\text { Ridley and } \\
\text { Baker (1982) }\end{array}$ \\
\hline $\begin{array}{l}\text { Time spent in } \\
\text { captivity }\end{array}$ & $\begin{array}{l}\text { Time has an influence on abnormal behaviours, } \\
\text { which can change in form with age; these } \\
\text { behaviours can also lose elements of the } \\
\text { original behaviour pattern and evolve with time }\end{array}$ & $\begin{array}{l}\text { Lawrence and } \\
\text { Rushen (1993) }\end{array}$ \\
\hline Type of rearing & $\begin{array}{l}\text { Hand-reared animals seem to have a greater } \\
\text { tendency to develop abnormal behaviours than } \\
\text { bears that have been mother reared }\end{array}$ & $\begin{array}{l}\text { Marriner and } \\
\text { Drickamer } \\
\text { (2005) }\end{array}$ \\
\hline Life experience & $\begin{array}{l}\text { The variety of experiences that occur during the } \\
\text { lifetime of every animal (e.g. isolation or poor } \\
\text { environment) can provoke the manifestation of } \\
\text { abnormal behaviours }\end{array}$ & $\begin{array}{l}\text { Fernandez } \\
(2010)\end{array}$ \\
\hline
\end{tabular}

more prevalent in spring than in summer (Ames, 1993; Kolter \& Zander, 1995). Another publication in American black bears $U$. americanus determined a seasonal variation in abnormal behaviours and his relationship with two species typical behaviours which were mate-seeking behaviour predominately in the late spring and foraging behaviour in late summer and autumn (Carlstead \& Seidensticker, 1991). There is not any publication that describes the relationship between abnormal behaviour seasonal variation and the space use.

It is crucial to determine the importance of the development and potentiation of the seasonal variations in captive brown bears in order to improve animal welfare and avoid the development of abnormal behaviours. If there are seasonal variations in abnormal behaviours possibly there might be also seasonal variations in other kind of behaviour (e.g. breeding, feeding or rearing).

The aim of this study was describing different aspects of the abnormal behaviours developed by two brown bear females at Barcelona Zoo: individual differences and seasonal variations of the duration, intensity, occurrence and space use. This kind of information can be useful in order to improve captive bear management because these animals are more susceptible to develop abnormal behaviours. These behaviours are one of the main concerns for professionals implicated in captive animal welfare. 


\section{Materials and Methods}

\section{Animals and Housing}

The two brown bear females studied at Barcelona Zoo arrived from the Parque de la Naturaleza de Cabárceno (Cantabria, Spain) in November 2003. The young $q$ was born in Cabárceno on 1 March 1994 and reared by her mother. The older female's birth type, location, date of birth and type of rearing were unknown because she was born before Cabárceno was opened in 1990. The hybrid status of both females is also unknown.

At Cabárceno these two females were housed together with 80 other brown bears in a semi-free roaming reserve for animals. The enclosure was a naturalized mountainous space belonging to an old iron mine and had a total area of 63 ha. The diet consisted of fruit, vegetables and meat provided once a day when a vehicle entered the enclosure. The space did not have any indoor areas and no enrichment programme was provided.

During this study at Barcelona Zoo, the two bears were housed together in a moat-style, semi-naturalized enclosure with a structure originally made from cement and a total area of $230 \mathrm{~m}^{2}$ (see Fig. 1). A wall divided the enclosure with an opening to connect the two parts, each of which had an aquatic zone for the animals to drink and bathe. The features in each enclosure included live trees, bushes, several large stones, large overturned logs for climbing, and several terraces at different levels with a natural substrate of gravel, sand and

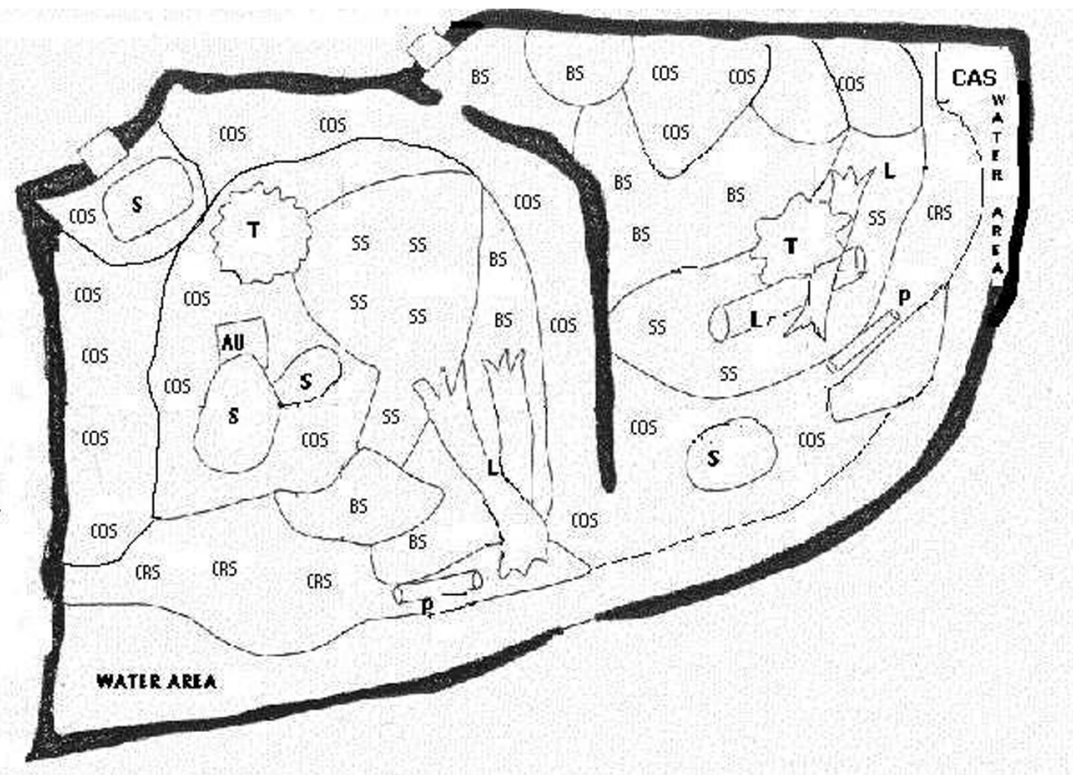

Fig. 1. Diagram of the enclosure for brown bears. AU, honey dispenser; BS, bark substrate; CAS, water fall; COS, concrete substrate; CRS, crushed stone substrate; L, logs; P, PVC pipe; S, stones; SS, sand substrate; T, tree. 
bark. The indoor areas were off-view cement cages with a drinking trough and bath (total surface area of $10 \mathrm{~m}^{2}$ each) (Soriano, Ensenyat, Serrat, \& Maté, 2006).

\section{Daily Management}

The management protocol allows the bears to go into their outdoor enclosures according to the hours of daylight (between 9:00 a.m. and 4:00 p.m. in spring; 9:00 a.m. to 8:00 p.m. in summer; 9:00 a.m. to 7:00 p.m. in autumn). The diet offered was seasonally unvaried and consisted of $8 \mathrm{~kg}$ of fruit and vegetables, $4 \mathrm{~kg}$ of meat (a mixture of horse, chicken and veal), $2 \mathrm{~kg}$ of dog chow and $1 \mathrm{~kg}$ of bread once a day for each bear, provided in the indoor areas in the evening. The old $q$ and the young $q$ slept separately in their respective indoor enclosures.

During the study phase, the animals took part in a twice-daily enrichment session. Each bear received the same enrichment device per session. During the first session, the keeper put the enrichment device in the enclosure before the animals were let into the space, at around 9:00 a.m. The second enrichment device was prepared by the keeper around 1:00 p.m. and was thrown into the enclosure from the visitor viewing area. The schedule for different enrichment devices for both sessions consisted of 31 devices, two of which were used each day of the month, following the same pattern during all the months of study. In addition, there were different kinds of enrichment devices; for example, (1) feeding, which provided elements that contained food, such as live fish [the feeding of live vertebrates is illegal in some countries], vegetables inside a sack or fruit inside traffic cones; (2) sensory, elements that maximize olfactory capabilities, such as different spices or the faeces of herbivores; and (3) occupational, items that maximize the physical and manipulative capabilities, such as balls, tyres or traffic cones (Soriano, 2013).

These animals did not have any training programme that would facilitate veterinary practices or body maintenance, such as foot or dental care.

\section{Abnormal Behaviours}

In February 2004, veterinary examination of these two females was carried out to discount physical disease as a potential factor influencing behaviour. The diagnoses estimated that the undesirable behaviours observed in these bears were considered abnormal.

Each bear demonstrated a different type of abnormal behaviour, on the one hand the old $q$ showed an oral abnormal behaviour and on the other hand, the young o developed a locomotor stereotypy. The old $o$ displayed episodes of biting a tree trunk that was part of the enclosure furniture. The description of this behaviour was the animal, in a four-legged position, partly introduced its mouth over the tree, and repeatedly opened and closed its mouth, tightening its jaw against the base of the trunk. This behaviour was classified as a 'state', because it had a meaningful duration and it could be timed with a stopwatch (Fig. 2A) (Lehner, 1996). The young o demonstrated a behaviour that was repetitive and of short duration, which consisted of abruptly lifting the head upward and/or to the side in a swinging, often circular arc, or dipping the head to the ground without breaking stride while walking. This action has been described in Giant pandas and was named 'head-toss' 

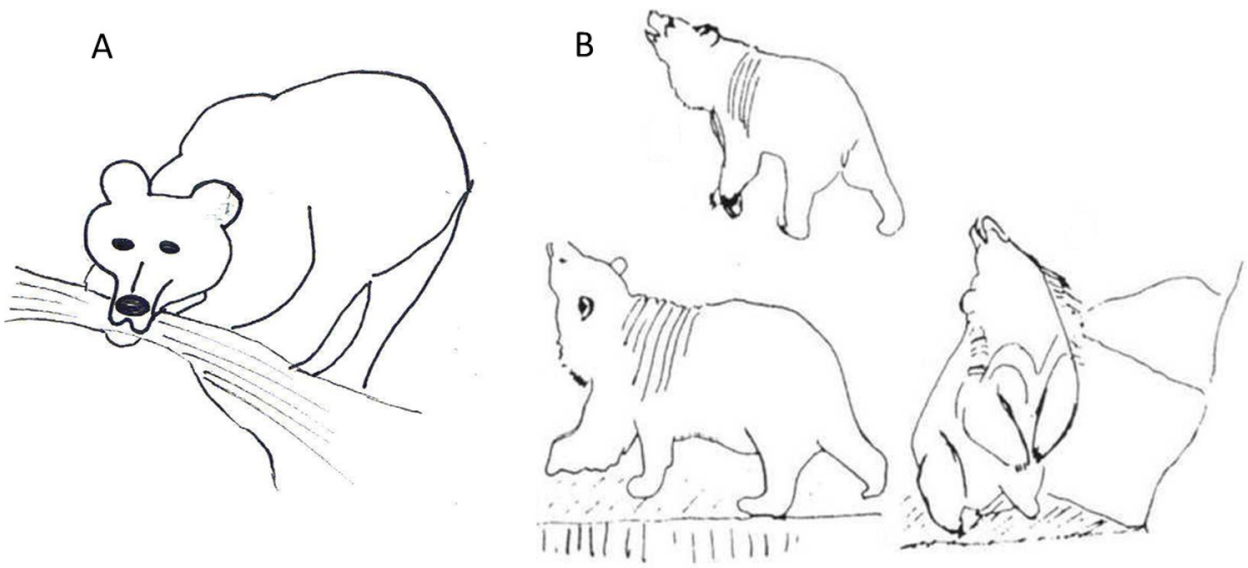

Fig. 2. Diagram of abnormal behaviours for brown bears: A. Old $\circ ;$ B. Young $q$.

(Lindburg et al., 2003). This behaviour was classified as an 'event', defined as a momentary behaviour (only lasting $5 \mathrm{~s}$ ) (Fig. 2B) (Lehner, 1996).

\section{Data Collection}

The study period was from March to December 2004. The observation sessions lasted one-hour and 63 hours of observations were recorded using a multi-focal and continuoussampling method (Martin \& Bateson, 2007). The studied variables included:

1. Seasonal periods: 21 hours of observation were conducted within each season: spring (30 March-7 June 2004), summer (28 June-16 September 2004) and autumn (22 September-20 December 2004).

2. Abnormal behaviours: five different aspects of this variable were studied in each session: (1) percentage of time invested on abnormal behaviour; (2) duration (sec), defined as the amount of time the bear engaged in the abnormal behaviour and was only measured for the old female's episodes; (3) intensity ( $\mathrm{sec}$ ), defined as the time that elapsed between two consecutive abnormal states or events; (4) occurrence, defined as the number of abnormal states or events observed during each session; and (5) space use frequency, defined as animal enclosure localization meanwhile the bear showed the abnormal behaviours. The enclosure was divided into eight similarly sized zones from Zone 1 to Zone 8 (Fig. 3).

\section{Data Analysis}

All data analyses were calculated using the Statistical Package for the Social Sciences (SPSS Inc., Chicago, IL 60606, USA) Version 21.0 for Windows. Normality was assessed using Kolmogorov-Smirnov test. A rejection criterion of $P<0.05$ was applied to all tests. The relationship between seasonal periods and the duration, intensity and occurrence were obtained through the Kruskal-Wallis test (Lehner, 1996). Meanwhile, the relationship 


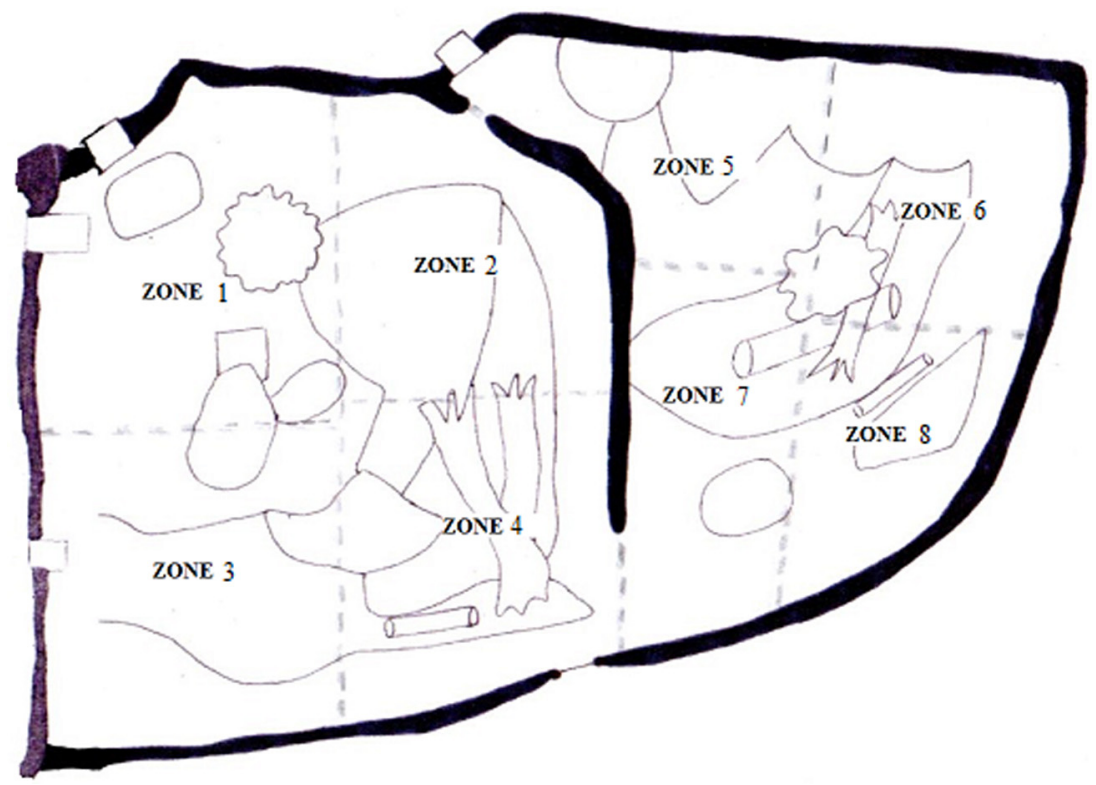

Fig. 3. Diagram of the enclosure for brown bears showing the division of the areas for the study of space use.

between the seasonal periods and the use of space were obtained through chi-square test. The adjusted residual statistic used had an absolute value of 1.96 for a normal distribution (Haberman, 1978).

\section{Results}

For both females the $\%$ of time invested on abnormal behaviour was higher in spring followed by summer and autumn (old $\%$; autumn: $8.10 \%$; spring: $27.74 \%$; summer: $9.34 \%$; young ; autumn: $7.50 \%$; spring: $11.75 \%$; summer: $9.12 \%$ ).

The mean and standard deviation of the duration, intensity and occurrence of abnormal behaviours per session for the two brown bear females are show in Table 2. The abnormal behaviour duration was statistically significant higher in spring than in summer and in autumn for both females. The intensity of abnormal behaviour only showed statistically significant difference for the young o. In this case, the intensity showed a statistically significant higher value during autumn than in summer and in the spring. The occurrence of abnormal behaviours showed statistically significant values for both females. The old $q$ showed a higher value in autumn than in summer and in the spring. However, the young o showed a higher value in spring than in summer and autumn (Table 3 ).

In relation to space use, the old o always developed the abnormal behaviour in the Zone 4 which frequency was 54 bouts in autumn, 47 bouts in spring and 49 bouts in summer. 
Table 2. Mean \pm standard error of mean (SEM) for the duration, intensity and occurrence of abnormal behaviours for each seasonal period and session in two Brown bear Ursus arctos females: $n$ old $q=137 ; n$ young $q=4283$ (where $n=$ number of observed episodes in the old $q$ and events in the young $\circ$ ).

\begin{tabular}{lccc}
\hline & $\begin{array}{l}\text { Duration (sec) } \\
\text { Mean } \pm \text { SEM }\end{array}$ & $\begin{array}{l}\text { Intensity (sec) } \\
\text { Mean } \pm \text { SEM }\end{array}$ & $\begin{array}{l}\text { Occurrence (no. of } \\
\text { abnormal behaviours) } \\
\text { Mean } \pm \text { SEM }\end{array}$ \\
\hline $\begin{array}{l}\text { OLD }+ \\
\text { Autumn }\end{array}$ & $268.6 \pm 31.0$ & $87.1 \pm 17.0$ & $53.7 \pm 6.2$ \\
Spring & $1081.7 \pm 111.3$ & $207.1 \pm 37.8$ & $2.1 \pm 0.3$ \\
Summer & $391.4 \pm 61.9$ & $299.5 \pm 58.8$ & $2.8 \pm 0.5$ \\
YOUNG $\$$ & & & $1.9 \pm 0.5$ \\
Autumn & $290.6 \pm 81.5$ & $310.7 \pm 66.3$ & $84.6 \pm 7.2$ \\
Spring & $422.9 \pm 35.9$ & $41.2 \pm 2.7$ & $65.7 \pm 7.9$ \\
Summer & $328.3 \pm 39.6$ & $64.1 \pm 12.5$ & \\
\hline
\end{tabular}

Table 3. Kruskal-Wallis values that show the effect of seasonal period on the duration, intensity and occurrence for two Brown bears.

\begin{tabular}{|c|c|c|c|c|c|c|c|c|c|}
\hline & \multicolumn{3}{|c|}{ Duration (sec) } & \multicolumn{3}{|c|}{ Intensity (sec) } & \multicolumn{3}{|c|}{$\begin{array}{l}\text { Occurrence (no. of } \\
\text { abnormal behaviours) }\end{array}$} \\
\hline & $H$ & d.f. & $P$ & $H$ & d.f. & $P$ & $H$ & d.f. & $P$ \\
\hline Old $q$ & 54.51 & 2 & $0.00^{* *}$ & 2.79 & 2 & 0.24 & 15.70 & 2 & $0.00^{* *}$ \\
\hline Young o & 733.02 & 2 & $0.00^{* *}$ & 810.59 & 2 & $0.00^{* *}$ & 733.02 & 2 & $0.00^{* *}$ \\
\hline
\end{tabular}

** Statistically significant differences $P<0.05 ; H$, Kruskal-Wallis test; d.f., degrees of freedom.

The young $o$ use of space showed statistically significant differences during the seasonal periods $\left(X^{2}=671.88 ; d f=14 ; P=0.00 * *\right)$. This female use more frequently zone 6 than the others. In autumn, this female showed abnormal behaviour with statistically differences more frequently in Zones 1, 2, 3, 4 and 5. In spring, the young $\circ$ developed abnormal behaviour with statistically differences more frequently in Zones 6 and 8. In summer, this female showed abnormal behaviour with statistically differences more frequently in Zones 6 and 7 (Fig. 4).

\section{Discussion}

The abnormal behaviours in the females of this study showed individual patterns. The young o showed a locomotor stereotypy also observed in other studies in brown bears (Spendrup \& Larsson, 1997), Polar bears (Ames, 1993; Hare, 1995; Fernandez, 2010) and American Black bears (Carlstead \& Seidensticker, 1991). Both types of abnormal 


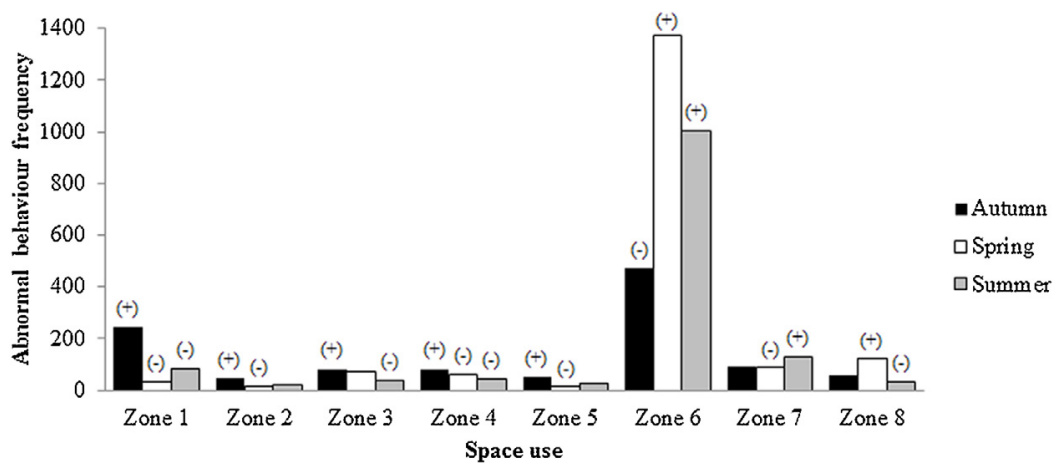

Fig. 4. Frequency of the space use during abnormal behaviour for each seasonal period in the young brown bear.

behaviours were also observed in Giant Pandas (Lindburg et al., 2003) and brown bears (Montaudouin \& Le Pape, 2005; Soriano, Vinyoles, \& Maté, 2016).

On the one hand and taking into account the unacceptable abnormal behaviour value higher than $10 \%$ described by Broom (1983), the unacceptable welfare values for both females of this study would be observed in spring (old $\%$ : $27.74 \%$; young : $11.75 \%$ ). However, these values would be acceptable in autumn and summer for both females. On the other hand, Montaudouin and Le Pape (2005) encoded the amount of stereotypy in: (1) no stereotypy; (2) low: less than $21 \%$ of time. In this case, it would be included the percentages of time invested in abnormal behaviour for both females in autumn (old o: 8.10\%; young \%: $7.50 \%$ ) and summer (old $\%: 9.34 \%$; young $\%: 9.12 \%$ ) and only the percentage of young o in spring $(11.75 \%)$; (3) medium: $21 \%$ to $45 \%$ of time. It was only observed for the old o during spring (27.74\%); and 4 ) high more than $45 \%$ of time. It was not observed in this study.

The study of Ames (1993) in Polar bears also described individual patterns of abnormal behaviours and also seasonal variations in the four periods - spring, summer, autumn and winter-. This study included five polar bear males and eight polar bear females which showed six different kinds of locomotor stereotypy on land and in water. There was a substantial variation in the amount of stereotypic behaviour for the females, levels ranged from $0 \%$ to $59.9 \%$ and for the males ranged from $0 \%$ to $45 \%$. In this case the lowest percentage of stereotypic behaviour was lower than brown bears of this study and highest level is higher, too. The duration of these behaviours ranged from $8 \mathrm{sec}$ to $50 \mathrm{sec}$ and it were different than observed in brown bears of this study that ranged from $5 \mathrm{sec}-$ for the young female's events- to $1743 \mathrm{sec}$ - for the old female's bouts-. One Polar bear male and one female showed the lowest level of abnormal behaviour in autumn and the highest level in spring coinciding with the results of this study. Moreover, one male and three females showed the lowest level of abnormal behaviour in autumn and three males and two females showed the highest level of abnormal behaviour in spring like the brown bears of this study. The other eleven Polar bears showed other variations of lowest and highest level of stereotyped behaviour (winter-spring; spring-autumn; winter-summer; autumn-winter; spring-winter; 
summer-winter; winter-autumn; summer-spring and; autumn-summer, respectively). Polar bears may be are more susceptible to develop stereotypic behaviours than the rest of the bears because is more difficult to reproduce in captivity the extreme seasonal conditions.

Carlstead and Seidensticker (1991) studied stereotypic pacing in an American black bear and observed two peaks related to mate-seeking behaviour predominating in the late spring and foraging behaviour in the late summer and fall. These results are very similar to the observed in the two brown bears of this study. In summer, the brown bears of this study may be are less susceptible to develop abnormal behaviours because the weather conditions are the same than in wild conditions and there is not mating or hibernation feeding necessities.

In spite of the winter period was not observed in this study of brown bears, it is known that the winter sleeping is a species-typical behaviour. Therefore, more specific studies are necessary to determine the role of hibernation in the welfare of these bears in zoological institutions. The hibernation period in bears is reliant on several different factors, including: (1) external factors, such as temperature and food availability; (2) internal factors, such as hormonal changes; and (3) a combination of factors (1) and (2) (Brown, 2009; Möstl \& Palme, 2002; Stirling, 1993; Ward \& Kynaston, 2003). The zoological institutions that house native species do not need to invest in large amount of money in air-conditioned or heated enclosures because the local weather conditions are the same. For example, at Ueno Zoological Gardens, Japan, there is a Japanese black bear $U$. thibetanus japonicus enclosure that was designed to include an indoor enclosure for hibernation, in order to encourage this species-typical behaviour. This specially designed den makes it possible to study the animals during hibernation and allows visitors to observe the bears even during the winter-sleeping period (Itoh, Ide, Kojima, \& Terada, 2010). There are also bears in zoological institutions that cannot hibernate because they are far away from their natural environment, such as the bears at Barcelona Zoo. In this case, the welfare implications of the inability to hibernate are unknown. In order to reproduce this particular species-typical behaviour in an institution, it would be necessary to adapt the husbandry and management protocols, and the design of the enclosure and dens.

In relation to the space use, the young o might use more frequently the zone 6 of the enclosure because it is the place most plane and more away from the visitor's area.

The expression of abnormal behaviours could be the result of the conditions in zoological institutions not reproducing accurately the conditions in nature, which permit the crepuscular brown bears to experience two seasonal peaks in species-specific behaviours (i.e. reproduction in spring and food store in autumn). In order to achieve these desirable variations and meet individual needs, there are factors that should be considered and should be included in the daily bear-management protocols (Soriano, 2013).

1. Diet composition. Some form of seasonal variation should be included to provision of diet, making it more similar to the variations that would be experienced in the wild. So, Brookfield Zoo managers implemented seasonal diets for brown bears successfully because the bears lost weight and are more active with less aggression and stereotypic behaviours (Watts, 2009). Moreover, some studies that applied feeding environmental 
enrichment in brown bears also reduced stereotypic behaviours (Grandia, Van Dijk, \& Koene, 2001; Larsson \& Tove, 1995; Morimura \& Ueno, 1999).

2. Enrichment programmes. Introduce seasonal variations into the design and provision of various enrichment techniques; for example, design a new enrichment device with salmon in summer or introduce dried fruits in autumn (Hare, 1995; Soriano, Vinyoles, \& Maté, 2013).

3. Facility design. Include climate-controlled facilities and dens with grasses, moss, leaves, conifer needles, and tree branches (Brown, 2009). There is also a crucial relationship between the size and layout of the enclosure and the expression of abnormal behaviours. When the facilities provided are larger and more natural, little abnormal behaviour are observed in bears in zoological institutions (Seidensticker \& Doherty, 1996; Soriano et al., 2006; Spendrup \& Larsson, 1997).

4. Social conditions. Studies should be carried out to determine whether the welfare of typically solitary individuals (as bears tend to be in nature) is worse when they are coexisting with conspecifics than when they are housed alone. This factor can be studied through behavioural (i.e. expression of abnormal behaviours, the use of space, proximity) or/and physiological (i.e. hormonal studies) indicators (Kleiman, Thompson, \& Baer, 2010). It is important to take season into account when institutions are participating in breeding conservation programmes (Fa, Funk, \& O'Connell, 2011).

5. Effect of visitors. In zoological institutions visitors have an effect on the expression of abnormal behaviour. This effect has been classified as: (1) positive, when the visitors decrease abnormal behaviours generally, and can be considered part of the enrichment programme (Claxton, 2011; Robson, 2004); (2) neutral, when visitors have no particular effect on the prevalence of abnormal behaviours (O'Donovan, Hindle, McKeown, \& O'Donovan, 1993; Soriano et al., 2013); and 3) negative, when the visitors increase the prevalence of abnormal behaviours or decrease the welfare of the animals (Cunningham, 2005; Owen, 2004; Soriano et al., 2013).

6. Veterinary care. The health of all animals in zoological institutions should be a high priority as ill health or disease may affect the manifestation of abnormal behaviours. Protocols should including providing vaccines, ensuring any injuries or illnesses are cured, and medication should be administered to avoid or treat parasite infestations (Irwin, Stoner, \& Cobaugh, 2013).

7. Training programmes. Where possible, in order to facilitate veterinary practices, such as administering vaccines or collecting biological samples (e.g. blood, hair, urine, faeces), and body maintenance (e.g. brushing hair or skin, filing nails or maintaining teeth), animals in zoological institutions should be trained to present various parts of their bodies for veterinary inspection (Ramirez, 1999).

8. Transportation. Moving animals between institutions is always stressful. It is essential that the welfare of the individual should not diminish either during or after transportation. Certain individual factors should also be taken into account before animal movements; for example, age, time spent in captivity, health and the management guidelines for the species (Rees, 2011).

All these factors influence the development and manifestation of abnormal behaviours. Studying each aspect in more detail would be necessary if we are to identify the optimal 
conditions for the maintenance of bears in the most artificial environments (Swaisgood \& Shepherdson, 2005). The ultimate aim of these kinds of studies is the reintroduction to natural habitats of bears from zoological institutions, as proposed by Vickery and Mason (2003b), especially because these species are at serious threat of extinction in their home territories.

\section{Acknowledgements}

We wish to thank Sandra Bals and Juani Melero for their collaboration on this study. In addition, we would like to thank our friends Esther Fernandez and Marc Escobar for their help writing this article. We also appreciate the English revision by Sudanshu Karandikar, Concha Santolaya and Susanna Flavià.

\section{References}

Ames, A. (1993). The behaviour of captive polar bears. UFAW Animal Welfare Research Report No. 5. Wheathampstead, Herts: Universities Federation for Animal Welfare.

Broom, D. M. (1983). Stereotypies as animal welfare indicators. Current Topics in Veterinary Medicine and Animal Science, 23, 81-87.

Brown, G. (2009). The bear almanac: A comprehensive guide to the bears of the world. Guilford, CT: The Globe Pequot Press.

Carlstead, K., \& Seidensticker, J. (1991). Seasonal variation in stereotypic pacing in an American black bear Ursus americanus. Behavioural Processes, 25, 155-161.

Cheng, J. S. C. (2003). The effects of feeding pattern change on Malayan sun bears. In V. J. Hare, K. E. Worley, \& B. Hammond (Eds.), Proceedings of the fifth conference on environmental enrichment (pp. 365-368). San Diego, CA: The Shape of Enrichment.

Claxton, A. M. (2011). The potential of the human-animal relationship as an environmental enrichment for the welfare of zoo-housed animals. Applied Animal Behaviour Science, 133, 1-10.

Criswell, A. R., \& Galbreath, G. J. (2005). Behavioral persistence in captive bears: A critique. Ursus, 16, $268-273$.

Cunningham, N. (2005). Visitor impact on the captive felid behaviour at Edinburgh Zoo. In A. Nicklin (Ed.), Proceedings of the seventh annual symposium on zoo research (pp. 159-164). London: British \& Irish Association of Zoos \& Aquariums.

Fa, J. E., Funk, S. M., \& O’Connell, D. (2011). Zoo conservation and biology. Cambridge.

Fernandez, E. (2010). Stereotypies and foraging: Appetitive search behaviors and stereotypies in captive animals. Saarbrücken.

Fox, M. W. (1968). Abnormal behavior in animals. Philadelphia.

Grandia, P. A., Van Dijk, J. J., \& Koene, P. (2001). Stimulating natural behavior in captive bears. Ursus, 12, 199-202.

Haberman, S. J. (1978). . Analysis of qualitative data (Vol. 1) New York.

Hare, V. J. (1995). Behavior modification of captive Alaskan brown bears (Ursus arctos gyas) using automated food dispensers. In B. Holst (Ed.), Proceedings of the second international conference on environmental enrichment (pp. 39-61). Copenhagen: Copenhagen Zoo.

Irwin, M. D., Stoner, J. B., \& Cobaugh, A. M. (2013). Zookeeping: An introductory to science and technology. Chicago.

Itoh, K., Ide, K., Kojima, Y., \& Terada, M. (2010). Hibernation exhibit for Japanese black bear Ursus thibetanus japonicus at Ueno Zoological Gardens. International Zoo Yearbook, 44, 55-64.

Kleiman, D. G., Thompson, K. V., \& Baer, C. K. (2010). Wild mammals in captivity: Principles and techniques of zoo management (2nd ed.). Chicago.

Kolter, L., \& Zander, R. (1995). Potential and limitations of environmental enrichment in managing behavioural problems of polar bears. In B. Holst (Ed.), Proceedings of the second international conference environmental enrichment (pp. 131-141). Frederiksberg: Copenhagen Zoo. 
Larsson, H. O., \& Tove, S. (1995). Daily activity and effects of feeding enriched environment in brown bear (Ursus arctos). In B. Holst (Ed.), Proceedings of the second international conference on environmental enrichment (p. 289). Frederiksberg: Copenhagen Zoo.

Lawrence, A. B., \& Rushen, J. (1993). Stereotypic animal behaviour: Fundamentals and applications to welfare. Wallingford: CAB International.

Lehner, P. N. (1996). Handbook of ethological methods (2nd ed.). Cambridge.

Lindburg, D. G., Swaisgood, R. R., Zhang, J., Narushima, E., \& Xiaoping, Z. (2003). Stereotyped behavior in the giant panda. In V. J. Hare, K. E. Worley, \& B. Hammond (Eds.), Proceedings of the fifth international conference on environmental enrichment (pp. 189-193). San Diego, CA: The Shape of Enrichment.

Marriner, L. M., \& Drickamer, L. C. (2005). Factors influencing stereotyped behavior of primates in a zoo. Zoo Biology, 13, 267-275.

Martin, P., \& Bateson, P. (2007). Measuring behaviour: An introductory guide (3rd ed.). Cambridge.

Mason, G. J. (1991). Stereotypies: A critical review. Animal Behaviour, 41, 1015-1037.

Mason, G. J., \& Latham, N. R. (2004). Can’t stop, won’t stop: Is stereotypy a reliable animal welfare indicator? Animal Welfare, 13, 57-69.

Mason, G. J., \& Rushen, J. (2006). Stereotypic animal behaviour: Fundamentals and applications to welfare. CABI: Oxford.

Meyer-Holzapfel, M. (1968). Abnormal behavior in zoo animals. In M. W. Fox (Ed.), Abnormal behaviour in animals (pp. 477-503). Toronto.

Montaudouin, S., \& Le Pape, G. (2005). Comparison between 28 zoological parks: Stereotypic and social behaviours of captive brown bears (Ursus arctos). Applied Animal Behaviour Science, 92, 129-141.

Morimura, N., \& Ueno, Y. (1999). Influences on the feeding behavior of three mammals in the Maruyama Zoo: Bears, elephants, and chimpanzees. Journal of Applied Animal Welfare Science, 2, 169-186.

Möstl, E., \& Palme, R. (2002). Hormones as indicators of stress. Domestic Animal Endocrinology, 23, 67-74.

O’Donovan, D., Hindle, J. E., McKeown, S., \& O’Donovan, S. (1993). Effect of visitors on the behaviour of female cheetahs Acinonyx jubatus and cubs. International Zoo Yearbook, 32, 238-244.

Owen, C. (2004). Do visitors affect the Asian short-clawed otter Aonyx cinerea in a captive environment? In C. Macdonald (Ed.), Proceedings of the sixth annual symposium on zoo research, 8th and 9th July 2004 (pp. 202-211). London: Federation of Zoological Gardens of Great Britain and Ireland.

Ramirez, K. (1999). Animal training: Successful animal management through positive reinforcement. Chicago, IL: Shedd Aquarium.

Rees, P. A. (2011). An introduction to zoo biology and management. Oxford.

Ridley, R. M., \& Baker, H. F. (1982). Stereotypy in monkeys and humans. Psychological Medicine, 12, 61-72.

Robson, C. (2004). Do visitors and weather affect captive Asian elephant (Elephas maximus) behaviour? In C Macdonald (Ed.), Proceedings of the sixth annual symposium on zoo research, 8th and 9th July 2004 (p. 296). London: Federation of Zoological Gardens of Great Britain and Ireland.

Seidensticker, J., \& Doherthy, J. G. (1996). In D. Kleiman, M. Allen, K. Thompson, \& S. Lumpkin (Eds.), Integrating animal behavior and exhibit design (pp. 180-190). Chicago.

Soriano, A. I. (2013). Wild ideas: Atlas fotográfico sobre el enriquecimiento ambiental. Almería: Editorial Círculo Rojo.

Soriano, A. I., Vinyoles, D., \& Maté, C. (2013). The influence of visitors on behavior and on the use of space in two species of Ursids: A management question? International Zoo News, 60, 341-356.

Soriano, A. I., Vinyoles, D., \& Maté, C. (2016). Long-term macroevaluation of environmental enrichment in three brown bears (Ursus arctos) at Barcelona Zoo. Journal of Applied Animal Welfare Science, 19, 49-61.

Soriano, A. I., Ensenyat, C., Serrat, S., \& Maté, C. (2006). Introducing a semi-naturalistic exhibit as structural enrichment for two brown bears (Ursus arctos). Does this ensure their captive well-being? Journal of Applied Animal Welfare Science, 9, 299-314.

Spendrup, S., \& Larsson, H. O. (1997). A comparative study of brown bear Ursus arctos in five different enclosure sizes and types. In V. J. Hare, \& K. E. Worley (Eds.), Proceedings of the third international conference on environmental enrichment (pp. 391-398). San Diego, CA: Shape of Enrichment.

Stirling, I. (1993). Bears: A complete guide to every species. London.

Swaisgood, R. R., \& Shepherdson, D. J. (2005). Scientific approaches to enrichment and stereotypies in zoo animals: What's been done and where should we go next? Zoo Biology, 24, 499-518.

Veasey, J. S., Waran, N. K., \& Young, R. J. (1996). On comparing the behavior of zoo housed animals with wild conspecifics as a welfare indicator. Animal Welfare, 5, 13-24.

Vickery, S., \& Mason, G. (2003a). Stereotypy and perseverative responding in caged bears: Further data and analyses. Applied Animal Behaviour Science, 91, 247-260.

Vickery, S., \& Mason, G. (2003b). Behavioral persistence in captive bears: Implications for reintroduction. Ursus, 14, 35-43. 
Ward, P., \& Kynaston, S. (2003). Bears of the world. New York, NY: Facts on File, Inc.

Watts, J. (2009). Case Study: Seasonal diets form brown bears (Ursus arctos) at Brookfield Zoo: Successful implementation led to reduce weight and improved behaviour. In A. Ward, K. Treiber, D. Schmidt, A. Coslik, \& M. Maslanka (Eds.), Proceeding of the eighth conference on zoo and wildlife nutrition. Tulsa, OK: AZA Nutrition Advisory Group.

Wechsler, B. (1991). Stereotypies in polar bears. Zoo Biology, 10, 177-188. 